\title{
Development of polymorphic microsatellite loci for a new fish species, Chinese sillago (Sillago sinica)
}

\author{
N. Song', L.Y. Wang', L.N. Yin' ${ }^{2}$, Z.Q. $\operatorname{Han}^{3}$ and T.X. Gao ${ }^{3}$ \\ ${ }^{1}$ Fisheries College, Ocean University of China, Qingdao, China \\ ${ }^{2}$ North China Sea Marine Engineering Prospecting Research Institute, \\ Qingdao, China \\ ${ }^{3}$ Fishery College, Zhejiang Ocean University, Zhoushan, China \\ Corresponding author: T.X. Gao \\ E-mail: gaotianxiang0611@163.com \\ Genet. Mol. Res. 15 (2): gmr.15027212 \\ Received September 14, 2015 \\ Accepted December 4, 2015 \\ Published April 4, 2016 \\ DOI http://dx.doi.org/10.4238/gmr.15027212
}

\begin{abstract}
Sillago sinica is a newly identified species belonging to Sillaginidae, Perciforms, and was found along the coast of China in 2011. In the present study, 81 microsatellite loci were isolated from an enriched genomic library, and 24 positive clones containing microsatellite repeats had adequate flanking sequences for the development of PCR primers. Sixteen of these primers were monomorphic or would not amplify. Eight were polymorphic in an examined population with the number of alleles per locus ranging from 2 to 14 . The number of observed and expected heterozygosities per locus varied from 0.125 to 0.958 and from 0.120 to 0.904 , respectively. The polymorphism information content ranged from 0.110 to 0.721 . All loci conformed to Hardy-Weinberg equilibrium $(P>0.05)$ after Bonferroni correction. There was no significant linkage disequilibrium between the eight polymorphic loci. These results suggest that these markers may be very useful for the characterization of natural populations of this species.
\end{abstract}

Key words: Microsatellite DNA; Sillago sinica; Polymorphic loci; New species 


\section{INTRODUCTION}

Sillago sinica, is a new marine fish species of China, which was found in the Bohai Sea (the Yellow River delta in Dongying), the Yellow Sea (the coastal region of Qingdao), and the East China Sea (the estuary of Feiyunjiang in Wenzhou) (Gao et al., 2011). S. sinica exhibits the same characteristics as other sillago species, which include the adults burying themselves in the sand when disturbed. Since it was first described, the morphological characteristics, sagittal otolith shape, and DNA barcoding of S. sinica have been described (Pan and Gao, 2010; Gao et al., 2011; Zhang et al., 2013). However, no genetic investigations based on microsatellite markers have been conducted until now because no suitable markers have been developed. Microsatellite markers are important tools that can be used to assess genetic diversity and develop molecular breeding techniques in fish because of their high level of polymorphism and co-dominant Mendelian inheritance (Chen et al., 2005). For the purpose of conserving the genetic resources and assessing the genetic diversity of $S$. sinica, it is essential to isolate polymorphic microsatellite markers for this species. In the present study, we developed eight polymorphic microsatellite markers isolated from a microsatellite enriched genomic library of S. sinica.

\section{MATERIAL AND METHODS}

A microsatellite-enriched partial library was constructed following the protocol of Hui et al. (2006) with a few modifications. Genomic DNA was extracted from muscle tissue using the standard phenol-chloroform method described by Sambrook et al. (1989), and then digested with Haelll. We used electrophoresis on a $1 \%$ low-melting-point agarose gel to isolate small fragments (500-1000 bp). A synthesized adaptor (21-mer: 5'-CTCTTGCTTGAATTCGGACTA3' and a phosphorylated 25-mer: 5'-pTAGTCCGAATTCAAGCAAGAGCACA-3') was ligated to the size-selected DNA fragments using T4 DNA ligase. Fragments containing microsatellite DNA were captured by hybridization to nylon membranes fixed with oligonucleotide (GA) ${ }_{15}$ and $(\mathrm{CA})_{15}$ probes. After washing to remove the non-simple sequence repeat fragments, the eluted single-stranded DNA contained the selected microsatellite DNA. The fragments were ligated into a pMD18-T vector, and the complexes were transformed into competent Escherichia coli $\mathrm{DH} 5 \alpha$ cells. The colonies were transferred to a new plate and screened with $(\mathrm{GA})_{15}$ and $(\mathrm{CA})_{15}$ probes labeled with DIG Oligonucleotide 30-End labeling kit 2nd generation (Roche). Positive signals were detected using the DIG luminescent detection kit for nucleic acids according to the manufacturer instructions (Roche).

In total, 24 PCR primer pairs were designed using the PRIMER 5 software (http://www. premierbiosoft.com). Twenty-four S. sinica individuals were collected from Dongying, Shandong Province, and used to test the polymorphism of these primer pairs.

PCR was performed in 25- $\mu \mathrm{L}$ volumes containing 10X PCR buffer, $200 \mu \mathrm{M}$ each dNTP, approximately $50 \mathrm{ng}$ genomic DNA, $200 \mu \mathrm{M}$ primers (forward and reverse), $1.5 \mathrm{mM} \mathrm{MgCl}_{2}$, and 1 $\cup$ Taq DNA polymerase (TakaRa). The thermo-cycling conditions were as follows: 5 min at $94^{\circ} \mathrm{C}$, followed by 35 cycles of $45 \mathrm{~s}$ at $94^{\circ} \mathrm{C}, 45 \mathrm{~s}$ at the annealing temperature listed in Table 1 , and 45 $\mathrm{s}$ at $72^{\circ} \mathrm{C}$, with a final extension at $72^{\circ} \mathrm{C}$ for $10 \mathrm{~min}$. After PCR amplification, the products were electrophoresed on $8 \%$ denaturing polyacrylamide gels at $12 \mathrm{~W}$ for $2-3 \mathrm{~h}$. The target bands were visualized by silver staining, and a reference marker of an 8-bp DNA ladder was used to identify allele size. 
Table 1. Levels of variability at eight polymorphic microsatellite loci in Sillago sinica.

\begin{tabular}{|c|c|c|c|c|c|c|c|c|c|c|}
\hline Locus & Primer (5'-3') & $\mathrm{Ta}\left({ }^{\circ} \mathrm{C}\right)$ & Repeat motif & No. of alleles & Size range $(b p)$ & $H_{0}$ & $\mathrm{HE}_{\mathrm{E}}$ & $\mathrm{P}$ & PIC & Accession No \\
\hline A47 & $\begin{array}{l}\text { F:AACAAACACGGTGCCCATC } \\
\text { R:AGACCCTGCTGCCCCTCAT }\end{array}$ & 50.0 & $(\mathrm{GA})_{23}$ & 2 & $189-195$ & 0.125 & 0.120 & 1.000 & 0.110 & KC489769 \\
\hline C64 & $\begin{array}{l}\text { F:CGACCAGGTGCGAAACGGACAA } \\
\text { R:GAGGAAAGCCAAGTGGGAGTAAAC }\end{array}$ & 57.4 & $(\mathrm{GA})_{7}(\mathrm{GA})_{7}(\mathrm{GA})_{6}$ & 3 & $244-258$ & 0.292 & 0.260 & 1.000 & 0.206 & KC489773 \\
\hline B54 & $\begin{array}{l}\text { F:GGCATCGGTAGTGACAGG } \\
\text { R:GGAGATTACTCGCCAAAG }\end{array}$ & 47.8 & $(\mathrm{GA})_{8}(\mathrm{GA})_{16}(\mathrm{CT})_{3}$ & 5 & 148-176 & 0.958 & 0.842 & 0.991 & 0.647 & KC489770 \\
\hline $\mathrm{C} 22$ & $\begin{array}{l}F: \text { FGAAGCAACCACATAGATAC } \\
\text { R:GGACCACCTGCCCTCA }\end{array}$ & 60.0 & $(\mathrm{CA})_{27}$ & 6 & $156-176$ & 0.542 & 0.724 & 0.023 & 0.606 & KC489772 \\
\hline C66 & $\begin{array}{l}\text { F:CTGACAGATAACCGAGTG } \\
\text { R:CAACCAAACCTGACGAG }\end{array}$ & 54.7 & $(\mathrm{CA})_{16}(\mathrm{CA})_{5}(\mathrm{CA})_{10}$ & 14 & 124-162 & 0.792 & 0.904 & 0.069 & 0.721 & KC489766 \\
\hline B55 & $\begin{array}{l}\text { F:TGAATGGTGGGGTAGGAC } \\
\text { R:TTGGATAGGAGGATGAGG }\end{array}$ & 50.0 & $(\mathrm{GA})_{9}(\mathrm{GA})_{14}(\mathrm{GA})_{11}$ & 3 & $202-212$ & 0.375 & 0.465 & 0.057 & 0.454 & KC489771 \\
\hline B45 & $\begin{array}{l}\text { F:GAGTAGGTGGGAAGGGAC } \\
\text { R:TTGGAGGACTGGGTTTAG }\end{array}$ & 53.0 & $(\mathrm{AC})_{4} \mathrm{TC}(\mathrm{AC})_{10}$ & 6 & $190-196$ & 0.375 & 0.55 & 0.077 & 0.434 & KC489767 \\
\hline A13 & $\begin{array}{l}\text { F:AGACAGGGAAAGAGTGAGA } \\
\text { R:TGGGAATAGAAAGGCA }\end{array}$ & 58.0 & $(\mathrm{GA})_{22}$ & 4 & $127-139$ & 0.625 & 0.738 & 0.260 & 0.681 & KC489768 \\
\hline
\end{tabular}

$\mathrm{Ta}=$ optimal annealing temperature; $H_{\mathrm{O}}=$ observed heterozygosity; $H_{\mathrm{E}}=$ expected heterozygosity; $\mathrm{P}=$ Hardy-Weinberg equilibrium; $\mathrm{PIC}=$ polymorphism information content.

\section{RESULTS AND DISCUSSION}

Of 130 positive clones, 81 were sequenced successfully using the M13 universal sequence primers with an $\mathrm{ABI} 3730$ genetic analyzer, and 81 sequences were found to contain microsatellite motifs. Twenty-four positive clones had an adequate flanking sequence that could be used to design primers. The hybrid clones, duplicates, and sequences with short unique regions flanking the microsatellite array were discarded. Of the 24 primer pairs, 16 were monomorphic or could not be amplified from the $24 \mathrm{~S}$. sinica individuals from Dongying. Eight loci showed obvious polymorphism, with allele numbers ranging from 2 to 14 (Table 1). The number of observed and expected heterozygosities per locus varied from 0.125 to 0.958 and 0.12 to 0.904 , respectively. The polymorphism information content ranged from 0.110 to 0.721 . Hardy-Weinberg equilibrium and linkage disequilibrium (LD) tests for each locus were conducted using GENEPOP 4.0 (Rousset, 2008). All eight polymorphic loci conformed to Hardy-Weinberg equilibrium after sequential Bonferroni correction (Rice, 1989). No significant LD was found in any of the eight polymorphic loci. The highly polymorphic loci identified in this study could be used for future evaluations of genetic variation in $S$. sinica or its closely related species.

\section{Conflicts of interest}

The authors declare no conflict of interest.

\section{ACKNOWLEDGMENTS}

Research supported by the grants from the Public Science and Technology Research of Oceanic Project (\#201305043 and \#201405010), the Scientific Startup Foundation of Zhejiang Ocean University (\#Q1505), and the China Postdoctoral Science Foundation (\#2013M540566).

\section{REFERENCES}

Chen SL, Liu YG, Xu MY and Li J (2005). Isolation and characterization of polymorphic microsatellite loci from an ESTlibrary of red sea bream (Chrysophrys major) and cross-species amplification. Mol. Ecol. Notes 5: 215-217. http://dx.doi. org/10.1111/j.1471-8286.2005.00880.x

Gao TX, Ji DP, Xiao YS, Xue TQ, et al. (2011). Description and DNA barcoding of a new Sillago species, Sillago sinica 
(Perciformes: Sillaginidae), from coastal waters of China. Zool. Stud. 50: 254-263.

Hui M, Bao Z, Zhan A, Hu X, et al. (2006). Ten polymorphic dinucleotide microsatellite markers of the noble scallop Chlamys nobilis. Mol. Ecol. Notes 6: 1033-1035. http://dx.doi.org/10.1111/j.1471-8286.2006.01420.x

Pan XZ and Gao TX (2010). Sagittal otolith shape used in the discrimination of fishes of the genus Sillago in China. Acta. Zootaxonom. Sin. 35: 799-805.

Rice WR (1989). Analyzing tables of statistical tests. Evolution 43: 223-225. http://dx.doi.org/10.2307/2409177

Rousset F (2008). genepop'007: a complete re-implementation of the genepop software for Windows and Linux. Mol. Ecol. Resour. 8: 103-106.http://dx.doi.org/10.1111/j.1471-8286.2007.01931.x PubMed

Sambrook J, Fritsch EF and Maniatis T (1989). Molecular cloning. A laboratory manual, 2nd eds. Cold Spring Harbor Laboratory Press, New York.

Zhang HY, Gao TX, Li J, Pan XZ, et al. (2013). Preliminary biological study on morphology of Sillago sinica. J. Shanghai Ocean Univ. 22: 17-22. 